\title{
Evaluation of Serum Lipid Profile and Malondialdehyde Levels in Obesed Adults
}

\author{
Ugochukwu C.P., ${ }^{1}$ Meludu S.C., ${ }^{2}$ Ugwu C.E., ${ }^{3}$ Ofor I.B., ${ }^{4}$ Onitsha E.N., ${ }^{5}$ Nezianya E U. ${ }^{6}$ \\ $1 *$ Department of Medical Laboratory Sciences, College of Health Sciences, Nnamdi Azikiwe University, Nnewi, Anambra State, Nigeria \\ ${ }^{2}$ Department of Biochemistry, College of Health Sciences, Nnamdi Azikiwe University, Nnewi, Anambra State, Nigeria \\ ${ }^{3}$ Department of Biochemistry, College of Health Sciences, Nnamdi Azikiwe University, Nnewi, Anambra State, Nigeria \\ ${ }^{4}$ Department of Medical Laboratory Services, Federal Medical Centre Yenagoa Bayelsa State, Nigeria \\ ${ }^{5}$ Department of Medical Laboratory Sciences, Niger Delta University, Amassoma, Bayelsa State, Nigeria \\ ${ }^{6}$ Department of Public Health, University of Lagos.
}

DOI: 10.29322/IJSRP.11.07.2021.p11596

http://dx.doi.org/10.29322/IJSRP.11.07.2021.p11596

\begin{abstract}
-
Their anthropometrics (weight, height, and blood pressure) were also taken using standardized media. The result showed a statistically significant $(\mathrm{P}<0.05)$ increase in the mean value of total Cholesterol, triglyceride and LDL-C, and a statistically significant $(\mathrm{P}<0.05)$ decrease in HDL-C in the obese group when compared with control (normal weight) group. There was also statistically significant $(\mathrm{P}<0.001)$ increase in atherogenic indices (TC/HDL-C, LDL-C/HDL-C) in the both the overweight and normal weight groups compared with the obese group. There was negative statistically significant $(\mathrm{P}<0.05)$ correlation between $\mathrm{TC}, \mathrm{LDL}-\mathrm{C}$ and atherogenic indices in relation to TAC. In the obese group, there were statistically significant positive correlations between TC, TC/HDL-C, LDL-C/HDL-C, LDL-C with MDA. There is significant $(\mathrm{P}<0.05)$ increase in the serum levels of MDA in relation to BMI while TAC showed a significant $(\mathrm{P}<0.05)$ decrease in relation to the BMI. The decrease in antioxidant defenses and increases in TC, TG and LDL-C in obese subjects reflects oxidative stress. This could be one of the mechanisms involved in the onset of diseases caused by obesity.
\end{abstract}

Index Terms- Body Mass Index, Lipid profile and Oxidative Stress

\section{INTRODUCTION}

$\mathrm{O}$ besity is a medical condition in which excess body fat has accumulated to the extent that it may have a negative effect on health, leading to reduced life expectancy and increased health problems ${ }^{(1)}$, it is assuming an epidemic dimension globally (2). Aside from being a potentially modifiable cardiovascular diseases (CVDs) risk factor on its own, this non-communicable disease predisposes to other CVD risk factors such as diabetes mellitus, hypertension and dyslipidemia among others ${ }^{(3)}$. Usually assessed by Body Mass Index (BMI), excess weight (Obesity and overweight) is a risk factor of atherosclerosis, and it is normally attributed in some extent to non-insulin dependent diabetes mellitus, arterial hypertension and hyperlipidemia. This atherogenic effect of obesity could be associated to several mechanisms which include inflammatory mechanisms, insulin resistance and stimulation of renin-angiotensin system commonly related to atherosclerosis processes ${ }^{(4,5)}$.
Lipid profile, a panel of investigations considered as obesity related-indicators is used to identify dyslipidemia, many forms of which are recognized risk factors for CVD. It measures total cholesterol, HDL cholesterol, LDL cholesterol, VLDL cholesterol and triglycerides. Lipids are insoluble in water but are soluble in alcohol and other solvents. When dietary fats are digested and absorbed into the small intestine, they eventually re-form into triglycerides, which are then packaged into lipoproteins. Dietary fats, including cholesterol, are absorbed from the small intestines and transported into the liver by lipoproteins called chylomicrons. After a 12-14 hour fast, chylomicrons are absent from the bloodstream $^{(6)}$. The liver removes the chylomicron fragments, and the cholesterol is repackaged for transport in the blood in very lowdensity lipoproteins (VLDLs), which eventually turn into lowdensity lipoproteins (LDL). LDL cholesterol (LDL-C) - the "bad cholesterol" - consists mainly of cholesterol ${ }^{(7)}$.

Dyslipidemia, commonly manifested as high plasma triglyceride levels, low HDL-C with normal LDL-C and high triglyceride level are important features observed in obesity and there is also a correlation between the degree of obesity and plasma level of LDL cholesterol and triglycerides ${ }^{(8)}$.Total antioxidant activity of serum is part of a tightly regulated homeostatic mechanism ${ }^{\left({ }^{(8)}\right.}$ When antioxidant defenses are weakened, as seen in obese people with greater energy expenditure than their thin counterparts due to the energy required to maintain an increased body mass ${ }^{(9)}$, risk of developing CVD may likely increase. Evaluation of total antioxidants capacity in body fluid has been used as one of the biological markers for monitoring oxidative stress in humans $(10)$.

Malondialdehyde(MDA) is one of the most frequently used indicators of lipid peroxidation. Previous studies have shown that the mean MDA levels are higher in obese individuals compared to nonobese healthy controls (11). It is also shown that obesity is associated with increases in endogenous lipid peroxides and oxidation of low-density lipoproteins ${ }^{(12)}$. Whether the increased lipoprotein oxidizability is due to enhanced oxidant challenge, or decreased antioxidant content, or changed lipoprotein composition is not fully explained.

Obesity with dyslipidemia has been shown to promote the onset of CVD. This link is strongly related to oxidative stress. Low levels of circulating high-density lipoprotein (HDL), enhanced 
clearance of HDL particles, increased post-prandial TG values, and elevated plasma very low density-lipoprotein (VLDL) levels promote ROS generation in the endothelium. In addition to a proinflammatory process, ROS can also directly damage lipids, proteins or DNA and modulate intracellular signaling pathways, such as mitogen activated protein kinases and redox sensitive transcription factors, causing changes in protein/lipid expression and, therefore, irreversible oxidative damage ${ }^{(13) .}$

\section{METHODS}

\section{Study Area}

The study was carried out in Nnewi, Anambra state Nigeria. Nnewi is located 6.02 latitude and 6.92 longitude and it is situated at elevation 151 meters above sea level. Nnewi is one of the largest cities in Anambra State, South Eastern Nigeria. It has two local government areas, Nnewi North and Nnewi South; Nnewi North is commonly referred to as Nnewi central. According to the Nigerian census the city spans over 1,076.9 square miles with an estimated population of 391,227. It is about 216 miles (or $347 \mathrm{~km}$ ) South of Abuja, the nation's capital and the principal inhabitants of the city are Igbos and their occupation is majorly trading and farming, although some few are involved in production.

\section{Subjects}

This study recruited a total of one hundred and ninety-eight apparently healthy volunteers, one hundred and thirty-four were overweight and obese while the other sixty-four were normal weight. They were within the ages of 18-60 and resident within Nnewi metropolis. Those that were disabled, having a weight of $<18.5 \mathrm{~kg}$ or having any metabolic condition were excluded from the study. All participants in this study gave Informed consent and ethical approval was obtained from the ethical committee of Nnamdi Azikiwe University Teaching Hospital, Nnewi. Anambra state.

\section{Sample Collection}

Blood samples $(6.0 \mathrm{~mL})$ were obtain from each subject between the hours of 08.00-10.00 after overnight fast and dispensed into plain bottles and allowed to clot for about two (2) hours. The samples were centrifuged at $3000 \mathrm{rpm}$ for five (5) min, after which serum was isolated from the clot and aliquoted into dry plain plastic screw-capped containers and stored frozen at $20^{\circ} \mathrm{C}$ prior to analyses

\section{Analysis of Biochemical Parameters}

The analysis for Total cholesterol was carried out colorimetrically using Enzymatic Endpoint Method (14). The cholesterol is determined after enzymatic hydrolysis and oxidation. The indicator quinoneimine is formed from hydrogen peroxide and 4-aminoantipyrine in the presence of phenol and peroxidase. While triglycerides are determined after enzymatic hydrolysis with lipases. The indicator is a stable red quinoneiminedye formed from hydrogen-peroxide, 4aminophenazone and 4-chlorophenol under the catalytic influence of peroxidase. Low density lipoproteins were precipitated quantitatively by the addition of phosphotungstic acid in the presence of magnesium ions. After centrifugation, the cholesterol concentration in the HDL (high density lipoprotein) fraction, which remains in the supernatant was determined. The LDLCholesterol concentration was extrapolated from Friedwald's formula ${ }^{(15)}$

LDL-Cholesterol=Total cholesterol-Triglyceride- HDLCholesterol/2.2. Malondialdehyde(MDA) is a product of lipid peroxidation. When heated with 2-thiobarbuturic acid (TBA) under alkaline condition, it forms a pink coloured product, which has absorption. Sample was assayed for TAC on spectrophotometer with a commercially available TAS kit ("Total Antioxidant Status" - TAS; Randox, Crumlin, UK), following the instructions of the manufacturers. Antioxidants in the sample reduce dark blue-green colored ABTS radical to colorless reduced ABTS form. The change of absorbance at $660 \mathrm{~nm}$ is related with total antioxidant level of the sample. The assay is calibrated with a stable antioxidant standard solution which is traditionally named as Trolox Equivalent that is a vitamin E analog (16).

\section{Data Analysis}

Data was reported as mean \pm SD. Statistical comparisons was made using the Student t-test in SPSS version 19. Pearson's correlation coefficients was also used to assess the relationship between total antioxidant capacity, malondialdehyde levels and lipid profile. The correlation between these parameters and the different BMIs was assessed by Spearman's correlation coefficient. In all analysis, $\mathrm{p}$

\section{Results}

Table 4.1 shows Antropometric variables in normal, overweight and obese individuals (Mean \pm SD).There was increase in age of the participants. This increase was statistically significant between groups $\mathrm{A}$ and $\mathrm{B}(\mathrm{P}=0.039)$ as well as $\mathrm{A}$ and $\mathrm{C}$ $(\mathrm{P}<0.001)$, but the increase between groups $\mathrm{B}$ and $\mathrm{C}$ was not statistically significant $(\mathrm{P}>0.05)$. There was however a significant increase $(\mathrm{P}<0.05)$ in the weight of the participants as well as in their BMI. The comparison of the weight and BMI in all the three groups also showed significant increase $(\mathrm{P}<0.05)$. However, the mean heights of the participants in the three groups followed an irregular pattern and when compared against each other there was no statistical significance. There was significant increase $(\mathrm{P}<0.05)$ in both systolic and diastolic blood pressure, between groups A and $\mathrm{C}$ as well as groups $\mathrm{B}$ and $\mathrm{C}$. The results also showed that DBP increased significantly $\mathrm{P}<0.05)$ in group $\mathrm{A}$ relative to group $\mathrm{B}$ while there was no significant increase $(\mathrm{P}>0.05)$ in SBP between groups A and B. Table 4.2 shows Serum lipid profile in the normal, overweight and obese individuals ((Mean+SD). TC, TG and LDL-C showed significant $(\mathrm{P}<0.05)$ increase in relation to $\mathrm{BMI}$, while HDL-C decreased relative to $\mathrm{BMI}$, this was only significant $(\mathrm{P}<0.05)$ between groups $\mathrm{B}$ and $\mathrm{C}$. The results show that there was no significant $(\mathrm{P}>0.05)$ increase in the mean $\mathrm{TG}$, HDL-C and LDL-C between groups A and B but TC was significantly $(\mathrm{P}<0.05)$ increased in these groups. However, there was a significant $(\mathrm{P}<0.05)$ increase in the mean of TC, TG and LDL-C when compared between groups $\mathrm{A}$ and $\mathrm{C}$ as well as groups $\mathrm{B}$ and $\mathrm{C}$. The results also indicated a significant $(\mathrm{P}<0.05)$ decrease in mean HDL-C between groups A and C. Table 4.3 shows Serum levels of total antioxidant capacity(TAC), malondialdehyde (MDA) in normal, overweight and obese individuals. There was significant $(\mathrm{P}<0.05)$ increase in the serum levels of MDA in relation to $\mathrm{BMI}$ while $\mathrm{TAC}$ showed a significant $(\mathrm{P}<0.05)$ 
decrease in relation to the BMI. There was no significant $(\mathrm{P}>0.05)$ decrease between normal weight and overweight individuals with respect to total antioxidant capacity (TAC) neither was there significant increase in mean serum levels of malondialdehyde between the normal weight and overweight group. However, group A (normal weight) and C (obese) as well as B (overweight) and $\mathrm{C}$ showed significant $(\mathrm{P}<0.05)$ decrease in $\mathrm{TAC}$, while groups $\mathrm{A}$ and $\mathrm{C}$ showed significant $(\mathrm{P}<0.05)$ increase in MDA. There was however no significant $(\mathrm{P}>0.05)$ increase in MDA between groups $\mathrm{B}$ and $\mathrm{C}$. There was significant $(\mathrm{P}<0.05)$ increase in Apo $\mathrm{B}$ in relation to $\mathrm{BMI}$, between groups $\mathrm{A}$ and $\mathrm{C}$ as well as groups $\mathrm{A}$ and $\mathrm{B}$ there were significant increase. However, between groups $\mathrm{B}$ and $\mathrm{C}$ the increase was not statistically significant $(\mathrm{P}>0.05)$. Table 4.4 shows serum levels of atherogenic Indexes in normal, overweight and obese individuals. There was significant
$(\mathrm{P}<0.001)$ increase in all three atherogenic indices and this also reflected in the comparison of group $\mathrm{A}$ (normal weight) and $\mathrm{C}$ (obese) as well as in groups $\mathrm{B}$ (overweight) and $\mathrm{C}$ (obese). However, groups A (normal) and B (overweight) showed no significant $(\mathrm{p}>0.05)$ increase in the atherogenic indices measured. There was significant $(\mathrm{P}<0.05)$ increase in relation to BMI and this increase was signify cant $(\mathrm{P}<0.05)$ in comparison between various groups.

Table 4.1: Anthropometric variables in Normal, Overweight and Obese Individuals

$\begin{array}{lcccc}\text { GROUP } & \text { AGE (years) } & \text { WEIGHT(Kg) } & \text { HEIGHT(m) } & \text { BMI }\left(\mathbf{K g} / \mathbf{m}^{2}\right) \\ \text { A } & 34.20 \pm 10.50 & 63 . .06 \pm 8.96 & 1.67 \pm 0.07 & 22.02 \pm 1.81 \\ \text { B } & 38.00 \pm 10.88 & 78.80 \pm 8.32 & 1.68 \pm 0.09 & 27.81 \pm 1.19 \\ \text { C } & 40.61 \pm 9.70 & 94.00 \pm 13.39 & 1.67 \pm 0.08 & 33.54 \pm 3.36 \\ \text { f-value } & 6.453 & 142.727 & 0.789 & 375.781 \\ \text { p-value } & 0.002^{*} & <0.001^{*} & 0.456 & <0.001^{*} \\ \text { A Vs B } & \mathrm{p}=0.039^{*} & \mathrm{p}<0.001^{*} & \mathrm{p}=0.448 & \mathrm{p}<0.001^{*} \\ \text { A Vs C } & \mathrm{p}<0.001^{*} & \mathrm{p}<0.001^{*} & \mathrm{p}=0.587 & \mathrm{p}<0.001^{*} \\ \text { B Vs C } & \mathrm{p}=0.146 & \mathrm{p}<0.001^{*} & \mathrm{p}=0.211 & \mathrm{p}<0.001^{*}\end{array}$

Results of Mean \pm Sd of Duplicate Readings; *=Statistically Significant $(\mathrm{P}<0.05)$. Results of Mean \pm Sd of Duplicate Readings; *=Statistically Significant $(\mathrm{P}<0.05)$. Group A: Normal Weight, Group B: Overweight, Group C: Obese.

Table 4.2: Serum lipid profile parameters in normal, overweight and obese individuals.

$\begin{array}{llccc}\text { GROUP } & \text { TC }(\mathbf{m m o l} / \mathbf{l}) & \text { TG }(\mathbf{m m o l} / \mathbf{l}) & \begin{array}{c}\text { HDL-C } \\ (\mathbf{m m o l} / \mathbf{l})\end{array} & \text { LDL-C (mmol/l) } \\ \text { A } & 4.58 \pm 0.82 & 0.85 \pm 0.32 & 1.19 \pm 0.37 & 3.01 \pm 0.74 \\ \text { B } & 4.89 \pm 1.06 & 1.03 \pm 0.56 & 1.23 \pm 0.37 & 3.23 \pm 0.97 \\ \text { C } & 5.40 \pm 0.78 & 1.33 \pm 0.60 & 1.11 \pm 0.31 & 3.60 \pm 0.82 \\ \text { f-value } & 14.739 & 15.015 & 2.209 & 8.265 \\ \text { p-value } & <0.001^{*} & <0.001^{*} & 0.113 & \mathrm{p}<0.001^{*} \\ \text { A Vs B } & \mathrm{p}=0.049^{*} & \mathrm{p}=0.051 & \mathrm{p}=0.463 & \mathrm{p}=0.151 \\ \text { A Vs C } & \mathrm{p}<0.001^{*} & \mathrm{p}<0.001^{*} & \mathrm{p}=0.189 & \mathrm{p}<0.001^{*} \\ \text { B Vs C } & \mathrm{p}=0.001^{*} & \mathrm{p}=0.001^{*} & \mathrm{p}=0.040^{*} & \mathrm{p}=0.012^{*}\end{array}$

Results of Mean \pm Sd of Duplicate Readings; $*=$ Statistically Significant $(\mathrm{P}<0.05)$. Results of Mean \pm Sd of Duplicate Readings; *=Statistically Significant $(\mathrm{P}<0.05)$. Group A: Normal Weight, Group B: Overweight, Group C: Obese, TC: Total Cholesterol, TG: Triglyceride, HDL-C: High Density Lipoprotein Cholesterol, LDL-C: Low Density Lipoprotein Cholesterol.

Table 4.3: Serum levels of total antioxidant capacity (TAC), malondialdehyde (MDA) in normal, overweight and obese individuals.

$\begin{array}{lll}\text { GROUP } & \text { TAC }(\mathrm{Umol} / \mathrm{l}) & \text { MDA }(\mathbf{n m o l} / \mathbf{l}) \\ \text { A } & 1036.10 \pm 195.43 & 1.58 \pm 0.83 \\ \text { B } & 1061.90 \pm 170.56 & 1.92 \pm 1.55\end{array}$




$\begin{array}{lll}\text { C } & 957.76 \pm 115.57 & 2.18 \pm 1.48 \\ \text { f-value } & 7.521 & 3.390 \\ \text { p-value } & 0.001^{*} & 0.036^{*} \\ \text { A Vs B } & \mathrm{p}=0.371 & \mathrm{p}=0.152 \\ \text { A Vs C } & \mathrm{p}=0.006^{*} & \mathrm{p}=0.010^{*} \\ \text { B Vs C } & \mathrm{p}<0.001^{*} & \mathrm{p}=0.259\end{array}$

Results of Mean $\pm \mathrm{Sd}$ of Duplicate Readings; *=Statistically Significant $(\mathrm{P}<0.05)$. Results of Mean \pm Sd of Duplicate Readings; *=Statistically Significant $(\mathrm{P}<0.05)$. Group A: Normal Weight, Group B: Overweight, Group C: Obese, TAC=total antioxidant capacity, MDA= Malondialdehyde

Table 4.4 Serum levels of atherogenic Indices in normal, overweight and obese individuals.

$\begin{array}{llll}\text { GROUP } & \text { TC/HDL-C } & \text { LDL-C/HDL-C } & \text { TG/HDL-C } \\ \text { A } & 4.15 \pm 1.32 & 2.30 \pm 1.20 & 0.78 \pm 0.37 \\ \text { B } & 4.26 \pm 1.46 & 2.88 \pm 1.31 & 0.91 \pm 0.56 \\ \text { C } & 5.29 \pm 1.71 & 3.59 \pm 1.44 & 1.33 \pm 0.77 \\ \text { f-value } & 11.716 & 7.393 & 15.703 \\ \text { p-value } & <0.001^{*} & 0.001^{*} & <0.001^{*} \\ \text { A Vs B } & \mathrm{p}=0.670 & \mathrm{p}=0.742 & \mathrm{p}=0.214 \\ \text { A Vs C } & \mathrm{p}<0.001^{*} & \mathrm{p}=0.001^{*} & \mathrm{p}<0.001^{*} \\ \text { B Vs C } & \mathrm{p}<0.001^{*} & \mathrm{p}=0.002^{*} & \mathrm{p}<0.001^{*}\end{array}$

Results of Mean \pm Sd of Duplicate Readings; *=Statistically Significant $(\mathrm{P}<0.05)$. Group A: Normal Weight, Group B: Overweight, Group C: Obese, TC: Total Cholesterol, TG: Triglyceride, HDL-C: High Density Lipoprotein Cholesterol, LDL-C: Low Density Lipoprotein Cholesterol.

\section{DISCUSSION}

The most important risk factors for cardiovascular disease consist of dyslipidemia, hypertension, obesity, physical inactivity, poor diet and smoking. Among these, lipid profile of plasma is the major risk factors and predictor for cardiovascular disease ${ }^{(17,18) \text {. }}$ Dyslipidemia describe as elevated plasma concentration of lipid (triglyceride (TG) and total cholesterol (TC) and their blood transporting lipoproteins; HDL- Cholesterol, LDL-Cholesterol, VLDL-Cholesterol) ${ }^{(19) .}$

This study demonstrated that there is a concordance between increased BMI and significant increase in value of LDL-C, TC and $\mathrm{TG}$ as well as systolic blood pressure and diastolic blood pressure and a significant decrease in HDL-C. This result is similar to the results of Kearn et al. (20) and several cross-sectional studies that showed chronic diseases like hypertension, diabetes, dyslipidemia and osteoarthritis are more prevalent in obese persons ${ }^{(21,5)}$. Strong scientific evidence indicates that there is a strong association between incidence of cardiovascular disease and high level of LDL-C and also low level of HDL-C (16). On the other hand, high level of TG has been related with an increased LDL-C particle and increased cardiovascular risk (17). On that basis, atherogenic dyslipidemia, defined as high LDL-C/HDL-C ratio and hyper TG, is associated with high cardiovascular risk (18). Obesity is associated with an increased risk of developing atherosclerosis.
Oxidative modification of lipoproteins may play an important role in the pathogenesis of atherosclerosis. Lipid peroxidation is involved in the oxidative modifications of low-density lipoproteins and this ultimately results in the formation of atherosclerotic lesions. Malondialdehyde is one of the most frequently used indicators of lipid peroxidation. Previous studies have shown that the mean MDA levels are higher in obese individuals compared to non-obese healthy controls (11). It is also shown that obesity is associated with increases in endogenous lipid peroxides and oxidation of low-density lipoproteins ${ }^{(12) .}$ In another study it was demonstrated that lipoprotein oxidizability is enhanced in obese young women, uncomplicated by hypertension, hypercholesterolaemia, diabetes or coronary heart disease ${ }^{(22) .}$ In our study we also found high MDA levels in obese subjects than in non obese. Whether the increased lipoprotein is due to enhanced oxidant challenge, or decreased antioxidant content, or changed lipoprotein composition is not fully explained. Our result in line with previous studies indicated that obesity is associated with increases in endogenous lipid peroxides. The indicator of lipid peroxidation-MDA - decreased with weight loss (23).

Dyslipidemia is defined as a condition of high blood cholesterol and TG levels that can increase the risk of cardiovascular disease, stroke, and other health problems. Obesity with dyslipidemia has been shown to promote the onset of cardiovascular disease. This link is strongly related to oxidative stress. In this study, malondialdehyde was strongly positively 
correlated with BMI, while total antioxidant capacity was negatively correlated to BMI. Several processes are involved in obesity caused by an overload of fat and carbohydrate meals. An increment of fat levels corresponds to increased energy storage, mitochondrial oxidation of nutrients, and oxidative stress, caused by an imbalance between reactive oxygen species generation and elimination by the cellular defense systems (24). Indeed, the mitochondrial and peroxisomal oxidation of fatty acids can produce reactive oxygen species in oxidation reactions, while another mechanism is over-consumption of oxygen, which generates free radicals in the mitochondrial respiratory chain coupled with oxidative phosphorylation. Lipid-rich diets are also capable of generating ROS because they can alter oxygen metabolism ${ }^{(24) .}$

A strong positive correlation was observed between TC, LDL-C and TC/HDL-C and LDL-C/HDL-C in relation to MDA as well as a strong negative correlation between LDL and MDA among obese adults which is in agreement with previous studies ${ }^{(25)}$ and reaffirmed the role of lipids in the pathophysiology of overweight and obesity as well as increasing accumulation of lipids in the obese group. However, the negative correlation of triglyceride (TG) was not significant, this does not agree with previous studies done ${ }^{(26)}$. Several studies have shown a robust association among obesity, altered redox state and inflammation; these studies have also shown that such alterations could also be the link between obesity and obesity-related diseases (including Type 2 diabetes, disorder, non-alcoholic liver disease disease and cancer). In previous study TAC attended be increased by various metabolic risk factors, especially overweight/obesity parameters (body mass index, body fat) and inflammation regardless of nutritional habits, nutrient intakes, physical activity and smoking. Increased levels of TAC in overweight adults may be due to oxidative stress generated by reactive oxygen species (27). However, in this study there was a significant decrease in TAC in relation to BMI. This is in line with Kelly et al. ${ }^{(28)}$ who reported a significant decrease in TAC among obese children with multimetabolic syndrome, this agrees with the findings of Wha $\mathrm{Ha}$ et al. (29).

However, TAC values in obese group were inversely associated with TC, TC/HDL-C, LDL-C/HDL-C and triglycerides and positively associated with HDL-C concentrations, independently of gender or age, this also is in line with previous studies ${ }^{(29) .}$ Low HDL-C has been reportedly associated with risk of cardiovascular disease but this research in accordance with Femlak et al. (30) emphasized the atherogenic role of dysfunctional HDL-C in obesity, this is as a result of HDL's interaction with VLDL mediated by hepatic triglyceride lipase in obesity ${ }^{(29) .}$

\section{CONCLUSION}

There is depleted antioxidant status and dyslipidemia in obese individuals increasing their risk of cardiovascular disease. Thus, to prevent such risks, it is most important to maintain a proper weight through a balanced diet. In addition, the inverse relationships of LDL-C with TAC is suggestive of an early stage involvement of antioxidant rich-diet in the link between redox state and atherogenesis.

\section{Financial Support and Sponsor}

No specific was provided for this study

\section{CONFLICT OF INTEREST}

The authors declare that there is no conflict of interest regarding the publication of this manuscript.

\section{ACKNOWLEDGEMENT}

The authors sincerely appreciate the Nnamdi Azikiwe University Teaching Hospital for approving this research work and also express profound gratitude to all the respondents whose informed consent for data and information collection enabled a successful completion of this study.

\section{REFERENCES}

[1] Ojofeitimi, E., Adeyeye, A., Fadiora, A., Kuteyi, A., Faborode, T., Adegbenro, C., Bakare, O., Setiloane, K. and Towobola, K. (2007): Awareness of obesity and its health hazard among women in a university community. Pakistan Journal of Nutrition;6 (5):502-505.

[2] World Health Organization, (2015): Obesity and overweight. Fact sheet $\mathrm{N}^{\circ} 311$. http://www.who.int/entity/mediacentre/factsheets/en/Updated January 2015.

[3] Michos, E., Nasir, K., Braunstein, J., Rumberger, J., Budoff, M., Post, W. and Blumenthal, R. (2010): Framingham risk equation underestimates subclinical atherosclerosis risk in asymptomatic women. Atherosclerosis; 184: 201-206

[4] Rocha, V...and Folco, E. (2011): Inflammatory concepts of obesity International Journal of Inflamation;20:111-115.

[5] Kalupahana, N. and Moustaid-Moussa, N. (2012): The renin-angiotensin system: A link between obesity, inflammation and insulin resistance. Obesity Review; 20:112

[6] Szczygielska, Anna \& Widomska, Sylwia \& Jaraszkiewicz, Magdalena \& Knera, Patrycja \& Muc, Kamil. (2003). Blood lipids profile in obese or overweight patients. Annales Universitatis Mariae Curie-Skłodowska. Sectio D: Medicina. 5. 343-9. ey/living/ Retrieved 2008-10-09

[7] Ugwuja, E., Ogbonna, N., Nwibo, A. and Onimawo, I. (2013): Overweight and Obesity, Lipid Profile and Atherogenic Indices among Civil Servants in Abakaliki, South Eastern Nigeria.Annals of Medical and Health Science Research;3(1):13-18.

[8] Murphy, M. P. (2009). How mitochondria produce reactive oxygen species. Biochem. J. 417, 1-13.

[9] Cao G, Prior RL.(1998) Comparison of differns analytical methods for assessing total antioxidant capacity of human serum. Clin Chem. ;44:13091315.

[10] Prazny, M., Skrha, J. and Hilgertova, J. (1999). Plasma malondialdehyde and obesity: is there a relationship? Clinical Chemistry Laboratory Medicine;37: 1129-1130.

[11] Mutlu-Turkoglu, U., Oztezcan, S., Telci, A., Orhan, Y., Aykac-Toker, G., Sivas, A. and Uysal, M. (2003). An increase in lipoprotein oxidation and endogenous lipid peroxides in serum of obese women. Clinical Exp Medicine.; 2: 171-174.

[12] Haslam, D. and James, W. (2005): Obesity. Lancet (Review) 366 (9492) 1197-209.

[13] Ceriello, A., Taboga C., Tonutti, L., Quagliaro, L., Piconi, L., Bais, D., da Ros,R., and Motz, E. (2002). Evidence for an independent and cumulativeeffect of postprandial hypertriglyceridemia and hyper-glycemia on endothelial dysfunction and oxidative stressgeneration: Effects of shortand long-term simvastatin treatment. Circulation; 106:1211-1218.

[14] Richmond, W. (1973) Preparation and Properties of a Cholesterol Oxidase from Nocardia sp. and Its Application to the Enzy-matic Assay of Total Cholesterol in Serum. Clinical Chemistry;19, 1350-1356.

[15] National cholesterol Education Program Working Group on Lipoprotein Measurement: Recommendations on Lipoprotein Measurement. NIH Publication No 95-3044, Bethesda, MD; 1995;31-34. 
[16] Koracevic D, Koracevic G, Djordjevic V, Andrejevic S, Cosic V. Method for the measurement of antioxidant activity in human fluids. J Clin Pathol. 2001 May;54(5):356-61.

[17] treatment with niacin and chromium on the liver of hyperlipemic rats. Biological Trace Elements Res; 101:219-229.

[18] Yang, R., Shi, Y., Hao, G., Li, W. and Le, G. (2008) Increasing oxidative stress with prog ressive hyperlipidemia in human: relation between malondialdehyde and atherogenic index. Journal of Clinical Biochemistry and Nutrition; 43:154-158.

[19] Kershaw, E. and Flier, J. (2004). Adipose tissue as an endocrine organ; Journal of Clinical Endocrin Metab; 89:2548-2556.

[20] Kearn, K., Dee, A., Fitzgerald, A., Doherty,E. and Perry, I. (2014). Chronic disease burden associated with overweight and obesity in Ireland: the effects of a small BMI reduction at population level. BMC Public Health;14:143

[21] Van Gaal, L., Vertommen, J. and De Leeuw, I.(1998) The in vitrooxidizability of lipoprotein particles in obese and non-obese subjects. Atherosclerosis; 137: 39-44.

[22] Shabnam, N., Mohammad, K., Majid, K.,Maryam A., Mohammadreza, J.,Gholamhasan K. and Maliheh, D. (2015). Atherogenic Index of Plasma (AIP): A marker of cardiovascular disease.Medical Journal of Islamic Republic of Iran; 29:240.

[23] Savini, I., Catani, M., Evangelista, D., Gasperi, V. and Avigliano, L. (2013) Obesity-Associated Oxidative Stress: Strategies Finalized to Improve Redox State. International Journal MolecularScience; 14: 10497-10538

[24] Fernández-Sánchez, A., Madrigal-Santillán, E., Bautista, M., Esquivel-Soto, J. and Morales onzález, Á. (2011). Inflammation, Oxidative Stress, and Obesity. International Journal of Molecular Science; 12: 3117-3132

[25] Nwagha U., Ikekpeazu E., Ejezie F., Neboh E. and Maduka I. (2010) Atherogenic index of plasma as useful predictor of cardiovascular risk among postmenopausal women in Enugu, Nigeria. African Health Sciences;10(3):248-252.

[26] Rao, V., and Kiran, R. (2011). Evaluation of correlation between oxidative stress and abnormal lipid profile in coronary artery disease. Journal of cardiovascular disease research, 2(1), 57

[27] Petelin A, Tedeschi P, Maietti A, Jurdana M, Brandolini V, Pražnikar ZJ. (2017) Total Serum Antioxidant Capacity in Healthy Normal Weight and Asymptomatic Overweight Adults. Exp Clin Endocrinol Diabetes. 2017 Jul;125(7):470-477.
[28] Wha Ha, A., Su Youn Jeong, S. Kang, N. and Kyoung Kim, W. (2014). Plasma adipocytokines and antioxidants-status in Korean overweight and obese females with dyslipidemia. Nutrition Research and Practice; 8(4):417424

[29] Essiarab, F., Taki, H., Lebrazi, H., Maati Sabri, M. and Saı"le, R. (2014). Usefulness of lipid ratios and atherogenic index of plasma in obese Moroccan women with or without metabolic syndrome. Ethnicity \& Disease; 24:207-2.

[30] Femlak, M., Gluba-Brzózka, A., Ciałkowska-Rysz, A. et al (2017). The role and function of HDL in patients with diabetes mellitus and the related cardiovascular risk. Lipids Health Dis 16,207

\section{AUTHORS}

First Author - Ugochukwu C.P, Department of Medical Laboratory Sciences, College of Health Sciences, Nnamdi Azikiwe University, Nnewi, Anambra State, Nigeria Second Author - Meludu S.C, Department of Biochemistry, College of Health Sciences, Nnamdi Azikiwe University, Nnewi, Anambra State, Nigeria

Third Author - Ugwu C.E, Department of Biochemistry, College of Health Sciences, Nnamdi Azikiwe University, Nnewi, Anambra State, Nigeria

Fourth Author - Ofor I.B, Department of Medical Laboratory Services, Federal Medical Centre Yenagoa Bayelsa State, Nigeria

Fifth Author - Onitsha E.N, Department of Medical Laboratory Sciences, Niger Delta University, Amassoma, Bayelsa State, Nigeria

Sixth Author - Nezianya E U, Department of Public Health, University of Lagos.

Corresponding Author: Onitsha Enebrayi Nelson E-mail: Brayi4life@gmail.com; Tel: +2347030603518 